\title{
Development of Physical and Optical Methods for In-shell Brazil Nuts Sorting and Aflatoxin Reduction
}

\author{
Fernanda Robert de Mello \\ Food Science and Technology Department \\ Center of Agricultural Sciences \\ Federal University of Santa Catarina, UFSC \\ PO Box 476, Florianopolis, SC, CEP 88034-001, Brazil \\ Tel: 55-48-3721-5386 \\ Vildes Maria Scussel (Corresponding author) \\ Food Science and Technology Department \\ Center of Agricultural Sciences \\ Federal University of Santa Catarina, UFSC \\ PO Box 476, Florianopolis, SC, CEP 88034-001, Brazil
}

Tel: 55-48-3721-5386_E-mail: vildescussel_2000@yahoo.co.uk

\begin{abstract}
Physical methods for mechanically in-shell Brazil nut sorting by color, size, density and inner deterioration were developed to assess nut quality and reduce aflatoxin contamination. Nuts were able to be sorted by color utilizing the standard shell chromaticity components $\mathrm{L}^{*}$, $\mathrm{a}^{*}$ and $\mathrm{b}^{*}$ at ranges of 31.51 to $48.64,4.09$ to 10.07 and 11.90 to 22.95 , respectively. It produced a homogeneous color batch and segregated the off-standard ones (darkest, lightest and stained). By size sorting utilizing three oval sectioned trays with the following dimensions $40 \times 25,35 \times 23$ and $20 \times 19.5 \mathrm{~mm}$ [length $\mathrm{x}$ width] and vibration, nuts were sorted into three sizes Groups: I, II and III for large, medium and small, respectively. Through density sorting the light nuts (shell/nut $<1.5$ ) which have inner mass reduction by fungi growth and/or dehydration, were separated with two compressed air streams from the healthy ones. Utilizing near infrared (NIR) spectrophotometry, the nuts inner deterioration was detected, with no need of de-shelling them at the wavelength range of 2200 to $2500 \mathrm{~nm}$. Any nut measurement detected, lower or higher than those sorting settings, was considered off-standard and rejected. Pools of the final standard and off-standard nuts were analyzed for aflatoxins by LC-MS/MS. No toxin was detected in the final standard batch up to the method LOQ $(0.08,0.09,0.10$ and $0.12 \mu \mathrm{g} / \mathrm{kg}$ for $\mathrm{AFB}_{1}, \mathrm{AFB}_{2}, \mathrm{AFG}_{1}, \mathrm{AFG}_{2}$, respectively). On the other hand, the off-standard rejected batch had $16.4 \mu \mathrm{g} / \mathrm{kg}$ of $\mathrm{AFB}_{1}$. These methods are important tools for building an in-shell Brazil nut sorting machine to assess nut quality and reduce aflatoxin contamination.
\end{abstract}

Keywords: In-shell Brazil nut, Deterioration, Sorting, Physical methods, Near infrared spectrophotometry, NIR, Aflatoxins

\section{Introduction}

Prevention of aflatoxin contamination in grains and nuts has not always been effective. The risk of aflatoxin contamination in Brazil nuts can occur, either in the forest or during the storage and it can vary with the year of harvest (Pacheco and Scussel, 2006; 2009). Nut contamination by fungi, especially the aflatoxigenic species of Aspergillus flavus is directly related to the climatic conditions (high humidity and heat) in the Amazon forest during the period of harvesting (wet season: December to May) (Pacheco and Scussel, 2006; 2007; 2009; Campos/Pas, 2004). The presence of aflatoxins is a concern for exporters of Brazil nuts especially since 1998, when the European Community (EC) reduced the maximum tolerance limit of total aflatoxins $\left(\mathrm{AFB}_{1}+\mathrm{AFB}_{2}+\mathrm{AFG}_{1}+\mathrm{AFG}_{2}\right)$ and $\mathrm{AFB}_{1}$ to 4 and $2 \mu \mathrm{g} / \mathrm{kg}$, respectively (EC, 1998; Newing and Harrop; 2000). 
Deteriorated in-shell nuts can present characteristics, which can be noted visually by consumers, such as visible mould, slimy, low weight, discoloration, irregular forms and, if the nut is rattled or right inside in the shell. Those characteristics can help to select the deteriorated/contaminated nuts from the healthy ones (Marklinder etal., 2005). The visual characteristics of Brazil nuts (size, weight, and colour) observed by consumers may indirectly indicate nut deterioration. However, when utilizing equipment for exact measurements of these nut characteristics, one can establish standards to facilitate the selection of healthy nuts and the rejection of deteriorated and/or contaminated ones. These parameters i.e., the characteristics of Brazil nuts for color, size and weight were measured and standards established (De-Mello and Scussel, 2007).

The knowledge of nuts and grain physical characteristics is essential to project, build and operate cleaning and sorting machines (Teixeira et al., 2003). The aim of the sorting process is to eliminate the grains or nuts with low quality, providing a product with better quality and standardize them in relation to their external characteristics. Furthermore, the sorting process can help to reduce aflatoxin contamination by the rejection of empty and broken grains, and those with color alteration and strange materials (Rohner, 1988; De Oliveira, 2006).

Studies have been reported evaluating the characteristics of deteriorated grains and nuts, in order to obtain data to distinguish them from healthy ones. Corn contaminated with mycotoxins showed lower density than non-contaminated ones (Dowell et al., 2002; Huff, 1980; Pearson and Wicklow, 2006), therefore, they could be separated by flotation in water or sucrose/salt solutions (Huff, 1980; Huff and Hagler, 1982; 1985; Rotter et al., 1995; Shetty and Bhat, 1999) or by air stream to sort the lighter corn from the heaviest ones (Huff, 1980). Pearson et al., in 1994 showed that early split pistachio which is more exposed to fungi and aflatoxin contamination is significantly different in relation to length, width and weight. From these characteristics it was possible to develop an image system for sorting earlier split pistachio nuts (Pearson and Slaughter, 1996).

Dowell et al. (2002), reported that the presence of fungi can affect some grain characteristics such as color, protein structure and oil content. Contaminated grains were rejected by color sorting machines and reduced $51 \%$ of the aflatoxin contamination in peanuts followed by hand sorting (Dickens and Whitaker, 1975; Zovico et al., 1999). Color sorting was more effective than fluorescence sorting for decontamination of peanuts (Pelletier and Reizner, 1992), however, fluorescence sorting was effective to reduce levels of aflatoxin contamination in pecans (Tyson and Clark, 1974) and pistachio (McClure and Farsaie, 1980). On the other hand, Steiner et al. (1992) reported pistachios that did not present fluorescence was contaminated with high aflatoxin levels and the opposite for Brazil nuts that presented fluorescence but were not aflatoxin contaminated.

The bright greenish yellow fluorescence (BGYF) was related as an efficient method for grain and nuts decontamination (Shotwell at al., 1975; Pearson et al., 2001), and it has been used by industries for sorting contaminated grains (Palomino et al., 1998).

Nowadays researches have been conducted to evaluate the behavior of near infrared (NIR) spectroscopy in the nuts and grains mycotoxin decontamination. During fungal growth, nutritive substances of the grains and nuts are metabolized and composition modified. Since grains and nuts contain high levels of lipids, the degradation of lipids also can influence the changes of NIR spectra of the nuts (Hirano et al., 1998). In addition, a fungal infected kernel would also scatter more light than a sound vitreous kernel because fungi growth can lead to produce endosperm powdery (Pearson et al., 2001). Wicklow \& Pearson (2006) achieved 85\% exaction in the selection of corn contaminated with aflatoxin from non-contaminated ones by NIR. Apart from sorting contaminated grains (Hirano et al., 1998), NIR can also be used to detect defects in almonds (Pearson, 1999; Pearson and Young, 2002) and pistachio (Haff and Pearson, 2006) or to predict their internal quality/matrix constituents (Wicklow and Pearson, 2006; Baye et al., 2006; Delwiches, 2003). Other non-destructive methods that have been used to evaluated grains and nuts quality are X-ray, acoustic and imaging (Pearson and Young, 2002; Haff and Pearson, 2007; Cetin et al., 2004; Pearson et al., 2008).

Regarding the Brazil nuts, the current sorting process is carried out manually and it occurs mainly after the first drying step (Pacheco and Scussel, 2009). That step is time consuming, labor intensive and not totally effective as deteriorated nuts are not visible in the in-shell nuts. Therefore, the development of a sorting machine is required.

The aim of this study was to develop physical and optical methods for in-shell Brazil nut mechanically sorting utilizing the nut characteristics (for color, size, density) reported by De-Mello and Scussel (2007), as well as to apply the NIR spectrophotometry for inner nut deterioration (De-Mello and Scussel, 2007) in order to assess nut quality and evaluate their efficiency to reduce aflatoxin contamination for future machine application.

\section{Materials and Methods}

\subsection{Samples}

In-shell, processed (dry) Brazil nuts, $65 \mathrm{~kg}$ (ca. 7137 nuts) obtained from the city of Manaus, state of Amazonas, Brazil (aflatoxin level: $5.62 \mu \mathrm{g} / \mathrm{kg}$; moisture content - mc: $6.2 \%$ ). 


\subsection{Chemicals}

Methanol and acetonitrile (HPLC grade) from Carlo Erba, ultra-pure water (MilliQ system) from Millipore and amonium acetate (analytical grade) from Vetec.

\subsection{Aflatoxin Standards}

$\mathrm{AFB}_{1}, \mathrm{AFB}_{2}, \mathrm{AFG}_{1}$ and $\mathrm{AFG}_{2}(1 \mathrm{mg})$ from Sigma.

\subsection{Equipment and Apparatus}

Color sorting: Sphere spectrophotometer, with dynamic rotational sampling, model SP60 was from X-Rite. Size classification: iron plates $(30 \times 30 \mathrm{~cm})$; sieves with $500 \mathrm{~mm}$ diameter with square sections $(38.0 \times 38.0 ; 25.5 \times 25.5$ and 19.0x19.0 mm for large, medium and small nuts, respectively), vertical milling machine, Turret; vibratory engine MR 110 and optic tachometer model TD 713 were from Instrutemp. Density sorting: poly(vinyl chloride) (PVC) pipe (75 and $500 \mathrm{~mm}$ for diameter and length, respectively); industrial fan was from Werner Hainlin; frequency inverter CFW-04 and anemometer model 445 were from Testo. Inner nut deterioration analysis: NIR spectroscope, model 900 PLS (wave length 1100-2500 nm) was from Femto. Aflatoxin analysis: by liquid chromatography - tandem mass spectrometry (LC-MS/MS) system comprised of a liquid chromatograph, model 1100 was from Agillent and mass/mass detector API 4000 equipped with electrospray (ESI) and atmospheric pressure chemical (APCI) ionization sources was from Applied Biosystems MDS SCIEX. Column: $\mathrm{C}_{8}$, particle size $5 \mu \mathrm{m}, 4.6 \mathrm{~mm}, 150 \mathrm{~mm}$ was from Zorbax. Other materials: digital caliper (6 inches) was from Lee; semi-analytical scale, model 440-53 was from Kern. Industrial Brazil nut-cracker, provided by CIEX factory, Manaus, AM, Brazil.

\subsection{Physical and Optical Methods for In-Shell Brazil Nuts Sorting}

The methods for shell color, size and density sorting were developed utilizing the Brazil nut standard characteristics of shell color ( $\mathrm{L}^{*}$, $\mathrm{a}^{*}$ and $\mathrm{b}^{*}$ ), nut sizes (length and width of Group I, II and III), weight (shell/nut ratio - S/N) reported by De-Mello and Scussel (2007). The NIR methodology for detecting inner nut deterioration utilized was that reported by the same authors in 2009. The methods are as follows:

Shell Color Sorting. The chromaticity values (achromatic component L* -relative darkness and lightness; chromatic component $\mathrm{a}^{*}$-green to red; chromatic component $\mathrm{b}^{*}$-blue to yellow) were obtained by photo-colorimetric readings on the in-shell nuts utilizing the standard range of 31.51 to $48.64,4.09$ to 10.07 and 11.90 to $22.95, \mathrm{~L}^{*}, \mathrm{a}^{*}$ and $\mathrm{b}^{*}$, respectively. Shell nut readings higher and lower than those ranges were discarded. Experiments were carried out in triplicates. The batch-rejected nuts were kept for final aflatoxin analysis. The selected nuts were then proceeded for size sorting.

Size Sorting. Using the nut length and width dimensions for Groups I, II and III of 53.2, 43.9 and $36.6 \mathrm{~mm}$ and 29.7, 26.5 and $18.8 \mathrm{~mm}$ for large, medium and small, respectively (De-Mello and Scussel, 2007), it was possible to study two methods for nut size classification. The first method was carried out utilizing 3 vibratory sieves (diameter $500 \mathrm{~mm}$ ) with square sections: $38 \times 38,25.5 \times 25.5$ and $19 \times 19 \mathrm{~mm}$ for the three size groups, respectively. The second method was carried out by building square trays $(500 \times 500 \mathrm{~mm}$ each) with specific sized and shaped sections. The sections were designed in an oval shape with the following dimensions for length and width: Tray I (large size) with 40 x $25 \mathrm{~mm}$; Tray II (medium size) with $35 \times 23 \mathrm{~mm}$ and Tray III (small size) with $20 \times 19.5 \mathrm{~mm}$. A fourth Tray was also built with no sections located at the base of the tray system to receive the discarded midget nuts, dust nut debris and other unwanted impurities that could come with the nut batch. The tray system was adapted to a vibratory engine (speed $171.7 \mathrm{rpm}$ ) for sorting the size nuts during vibration (Figure 1). Samples (5 groups of $13 \mathrm{~kg}$ each ie., ca. 1427 nuts/13 $\mathrm{kg}$ ) were submitted to size sorting tests with 5 minutes of vibration $(\mathrm{n}=5)$. Only the material that got onto the Tray IV, i.e., that passed through the three previous sectioned trays were kept for aflatoxin analysis. The three size classified nuts were submitted to the next step.

Density Sorting. According to the principle that light (low weight) in-shell nuts can be spoiled, i.e., have inner mass reduction due to fungi proliferation and/or dehydration thus lower weight (shell/nut ratio - $\mathrm{S} / \mathrm{N}<1.5$ ) than the healthy ones ( $\mathrm{S} / \mathrm{N}>1.5$ ) reported by De Mello and Scussel (2009), Brazil nuts after being classified by size, were sorted by density difference into (a) light (off-standard nuts = blown off nuts) and (b) heavy (selected nuts = not blown nuts) by applying compressed air. The aim of this sorting process was to reject nuts, which present weight lighter than $5 \mathrm{~g}$ (standard nut weight: 12.9, 8.8 and $6.3 \mathrm{~g}$ each size, respectively). A prototype system with compressed air with adjusted flow for blowing off deteriorated low weight ones was built using a pipe (diameter $75 \mathrm{~mm}$ and length: $500 \mathrm{~mm}$ ), which was applied to an industrial fan, airflow 5 to $20 \mathrm{~m} / \mathrm{s}$ and engine rotation of 1000 to $3000 \mathrm{rpm}$ (Baye et al., 2006; Delwiches, 2003). The compressed air provided by the industrial fan was canalized through the pipe. A sieve was adapted on the bottom of the pipe in order to hold the heavier nuts. The size classified in-shell Brazil nuts obtained from the previous sorting process were loaded continuously in the pipe and sorted by density. The rejected nuts i.e., the lighter that blew off were separated manually, weighed and kept for aflatoxin analysis. These rejected nuts were also checked by the next sorting process i.e., NIR. 
Inner In-Shell Nut Deterioration Detection. The method was carried out by applying the transmittance NIR spectrophotometry analysis in order to detected and segregate the nuts with inner deteriorations (off-standard). Therefore, the three sorting methods selected in-shell nuts were analyzed by scanning individually throughout their inner structures by an emitting NIR frequency. It passed through the whole in-shell nut (crossing one side of the shell through the inner nut endosperm and to the other shell nut side and reflected). It measured the variation in the inner nut structure in comparison to the readings of a standard (not presenting deterioration / healthy) nut (Pearson, 1999; Pearson and Young, 2002; Haff and Pearson, 2006). Thus nuts with wavelength readings between 2200 and $2500 \mathrm{~nm}$ that is considered the range for inner-deterioration by De-Mello and Scussel (2009) were segregated. The readings were taken from the three faces of each nut. The selected (no inner deterioration) and rejected (with inner deterioration) batches had individual nuts opened to check deterioration visually, and analyzed for aflatoxin. The rejected nuts from the previous sorting methods (color, size and density) were also NIR checked.

\subsection{Aflatoxin Analysis}

The methodology used was LC-MS/MS-APCI in the positive mode (Xavier and Scussel, 2008). LC conditions: $\mathrm{C}_{8}$ column, flow rate of $1 \mathrm{ml} / \mathrm{min}$, mobile phase of methanol/water $(55: 45, \mathrm{v} / \mathrm{v})$ held for 3 min then changed to methanol/water $(70: 30, \mathrm{v} / \mathrm{v})$ from 3-5 min. MS/MS: the APCI source operated at dissolvation temperature of $700^{\circ} \mathrm{C}$. Curtain gas was $15.0 \mathrm{psi}$, nebulizer gas at $55.0 \mathrm{psi}$, corona discharge needle current of $5 \mu \mathrm{A}$ and collision-activated dissociation (CAD) 10. The parent (and the two daughters) ions $\left(\mathrm{m} / \mathrm{z}\right.$ ) were selected for each toxin. For aflatoxin $\mathrm{B}_{1}$, $313.1 \mathrm{~m} / \mathrm{z}(241.10 ; 285.10)$; aflatoxin $\mathrm{B}_{2}, 315 \mathrm{~m} / \mathrm{z}(259.09 ; 287.20)$; aflatoxin $\mathrm{G}_{1}, 329.1 \mathrm{~m} / \mathrm{z}(200.05 ; 243.05)$ and aflatoxin $\mathrm{G}_{2}, 331.2 \mathrm{~m} / z(245.07 ; 231.20)$. The LOD and LOQ were obtained by finely grinding, homogenizing and spiking the nuts prior extraction with aflatoxins, at five concentrations ranging from 1 to $10 \mu \mathrm{g} / \mathrm{kg}$. The method LOD was defined by 3 times the signal/noise ratio and LOQ by 6 times the signal/noise. Five points were used to build an analytical curve, in order to obtain the R values for LOD and LOQ. Each point corresponded to a mean of five injections of each extract. The LOQ obtained were $0.08,0.09,0.10$ and $0.12 \mu \mathrm{g} / \mathrm{kg}$ for each toxin, respectively and 0.39 $\mu \mathrm{g} / \mathrm{kg}$ for total aflatoxins. Aflatoxins were analyzed in the batches (a) prior to the nut sorting; (b) after the total sorting process in a pool of the final: (b.1) selected and (b.2) rejected / off-standard nuts; as well as in the midget remained in the sorting Tray IV. The analysis was carried out in triplicate. The $m c$ was by gravimetry (AOAC, 2005). Figure 1 presents the chart flow of the in-shell Brazil nut sorting procedures and the steps that had aflatoxin analysis carried out.

The statistical analysis was carried out by analysis of variance-ANOVA- (Montgomery, 2001).

\section{Results and Discussion}

\subsection{Physical and Optical Methods for In-Shell Brazil Nuts Sorting}

The whole parameters of the physical and Optical methods developed for in-shell Brazil nuts sorting by shell color, nut size and density as well as the NIR measurements for nut internal deterioration, are shown in Table 1.

\subsubsection{Nut Shell Color, Size and Density}

Shell Color Sorting. When the shell color standard ranges for the shell chromaticity components $\mathrm{L}^{*}$, a* and b*, considered as acceptable color, were applied to the Brazil nut, it was possible to select the nuts with the standard, normal shell color (mean: L* 39.46, a* 7.91, b* 17.99). The off-standard ones were discarded i.e., any shell chromaticity component reading that was higher (mean: $\mathrm{L}^{*} 54.09$, a* 20.76, b* 24.93) or lower (mean: $\mathrm{L}^{*} 4.44$, a* 3.08, $\left.b^{*} 7.21\right)$ than those standard ranges set in the method, were separated from the main batch. The batch had improved its quality showing more homogeneous shell color for better acceptance by consumers. Color apart from nut external quality, may be an indirect way to identify fungal and mycotoxin contamination and a tool to be used for sorting machine development. It also had reduced the probability of having contaminated ones, shell color wise (De-Mello and Scussel, 2007). It was observed that the off-standard nuts presenting the readings for the darker and lighter and so for the stained ones, when the shell was opened they revealed more often deteriorated nuts (1 out of 4 nuts - RSD 39\%). On the other hand, deteriorated nuts were found in nuts that had shells presenting the standard color, and healthy nuts were found in stained shells. Therefore, regarding aflatoxin contamination and nut color sorting, the off-color segregation did not present a direct correlation thus was not enough and did not assure safety.

Size Sorting. When nuts were sorted /classified using the sectioned trays, it was possible to separate them into large, medium and small sizes. The nuts had their best size separation through the oval shaped sections trays than through the square sectioned sieves. Brazil nuts have irregular sizes and shapes and it was difficult to sort them through the square sections $(38 \times 3 ; 25.5 \times 25.5$ and 20x19.5 mm, respectively for each size). It was also not possible to predict the position and how the nuts would pass through those sections by length (horizontal position) or by width faces (vertical position), leading to blockage. Two or more small nuts getting on the big sections would block them and other nuts could not pass through to the following medium sized sections of Tray II. That also happened in the medium sections; consequently small nuts were wrongly classified as big and medium to the small sizes. Utilizing the oval shaped sections reduced the size classification error. It was observed that small nuts did not block the larger sections and easily passed through them 
without blocking and confusing the size classification. Thus the Brazil nut sizes were more correctly classified (with quite low SD and RDS\% ranging from 0.4 to 2.3 and 9.0 to $9.9 \%$, respectively) of the 5 repetitions of the portions (13 $\mathrm{kg}$ ). The largest nuts (nuts sizes $>50$, mean $53.2 \mathrm{~mm}$ ) didn't pass through the Tray I $(40 \mathrm{x} 25 \mathrm{~mm})$; the medium nuts (nut sizes: $40-50$, mean $43.9 \mathrm{~mm}$ ) passed the first tray but, did not pass through the Tray II $(35 \mathrm{x} 23 \mathrm{~mm})$, and consequently the smallest nuts (nut sizes: $>20<40$, mean $36.6 \mathrm{~mm}$ ) passed the second tray but didn't pass through the Tray III (size: $19.5 \times 20 \mathrm{~mm}$ ). Moreover, through those sections midget nuts (size $<20 \mathrm{~mm}$ ) and small particles (dust, dirt, pieces of shell) were able to pass through the 3 trays and were received in the non-sectioned Tray IV (Figures 2 and 3). The total time for nut sorting of $30 \mathrm{~kg}$ was $5 \mathrm{~min}$. The aflatoxin analysis of the material collected on Tray IV showed that they contained $2.21 \mu \mathrm{g} / \mathrm{kg}$ of $\mathrm{AFB}_{1}$. In fact those rejected materials can contribute to aflatoxins contamination, as they may contain deteriorated nut debris and aflatoxigenic fungi spores.

Density Sorting. From the range of compressed air speed studied (flow: 5 to $20 \mathrm{~m} / \mathrm{s}$ ) and engine rotations (1000 to 3000 $\mathrm{rpm}$ ), two standards of air speed for nut density separation was obtained: 10 and $11 \mathrm{~m} / \mathrm{s}$, using rotation of 1400 and $1792 \mathrm{rpm}$, respectively. From these speeds it was possible to sort nuts with mean density $10.34 \mathrm{~g}(\min 5.7, \max 15.3)$ and $8.13 \mathrm{~g}(\min 4.7, \max 13.9)$ with rather low SD and RSD of $3.98 \& 8.19 \%$ and $4.37 \& 9.34 \%$, respectively. For the rejected nuts, they were $9.94 \mathrm{~g}(\min 4.8, \max 12.8)$ and $7.26 \mathrm{~g}(\min 13.2, \max 15.8)$ with SD and \%RSD of $4.96 \&$ $3.36 \%$ and $6.88 \& 4.53 \%$ for the two air speeds, respectively. In fact low density $(\mathrm{S} / \mathrm{N}<1.5)$ nuts may be more prone to aflatoxin contamination than the high density ones (De-Mello and Scussel, 2007) and have been reported by other authors for grains and nuts (Dowell et al., 2002; Huff, 1980; Pearson and Wicklow, 2006). It is important to emphasize that, although, the lightest nuts blew off with the air stream, some heavy (healthy) nuts were also rejected (blown off) during the density sorting. That can be explained for the irregular shape of the Brazil nut. In order to get the Brazil nut floating, the air pushing force needed to be higher than the nut density. However, the pushing force is proportional to the nut geometry (air contact area). In conclusion, some big nuts that had more contact area (positioned during the air flow), could blow off easier and faster than the small ones, even if they were heavier than the big ones. Those rejected big nuts can be, either return to the batch and be density sorted again, or they can go to the factory de-shelling section to be used shelled. Different airflow may be required for each Brazil nut size, in order to avoid the blown off of some heavy (healthy) nuts despite of the sizes. This can be sorted out by utilizing previously size classified nuts.

\subsubsection{Inner In-Shell Nut Deterioration}

When the three sorting methods selected standard in-shell nuts were scanned individually throughout their inner structures by NIR spectrophotometry, it was possible to identify some nuts with higher wavelength readings at the range 2200 to $2500 \mathrm{~nm}$, corresponding to $5 \%$ of the total final sorted batch. That is the range to detect inner nut deterioration (De-Mello and Scussel, 2009). Those nut deteriorations are not visible by human eyes nor can be detectable by the previous sorting methods as the nuts are in-shelled. Those readings are indication that some in-shell nuts were not edible/safe as they were moldy.

That reading variation happens because fungi proliferation affects the nut integrity and its components (lipids and protein) producing a dark powdery endosperm, quite different from the vitreous and homogeneous endosperm nut. Those tissue alterations scatter the NIR beam reducing its transmittance when it crosses the entire in-shell nut material giving readings different of that obtained in the healthy nuts (Dowell et al., 2002; Wicklow and Pearson, 2006; Pearson, 1999; Pearson and Young, 2002).

As far as nut inner deterioration sorting by NIR and aflatoxin contamination are concerned, it was found a rather direct correlation in the nut batch used for this study. When aflatoxins were analyzed in the pool of healthy (no inner deterioration) nuts sorted (by NIR spectrophotometry), no toxin was detected up to the method LOQ in the healthy ones. However, $16.4 \mu \mathrm{g} / \mathrm{kg}$ of aflatoxin $\mathrm{B}_{1}$ was detected in the off-standard in-shell nuts (with inner deterioration). The final rejected batch concentrated the total aflatoxin content of the initial nut batch. Important to emphasize that the results on nut inner deterioration obtained by nut density (S/N ratio) sorting - De Mello and Scussel, 2007 - with compressed air corroborated to a certain extent to the NIR analysis; however the last (NIR) was more precise. That shows that those sorting methods used previously can still reject healthy nuts. However, they reduce in a certain extent the probability of aflatoxin contamination, even if not precisely. Despite of that the methods highly improved the nut batch visual quality.

\subsection{Aflatoxin Levels versus Physical and Optical Methods for In-Shell Brazil Nuts Sorting}

No aflatoxin was detected in the final batch of Brazil nut sorted by color, size, density and NIR. They were detected only in the pool of rejected (off-standard) nuts at level of $16.4 \mu \mathrm{g} / \mathrm{kg}$ of aflatoxin $\mathrm{B}_{1}$ corresponding to ca. $5 \%$ of the total initial nut batch (7135 nuts). The shell color sorting allowed to reduce the probability of having aflatoxin contamination, as the color off-standard shell nuts when had their shell opened, presented more often deterioration. However, deteriorated nuts were found in shell nuts having standard color, showing that color segregation was not efficient, aflatoxin wise, and did not assure safety. By size sorting it was observed that the nuts classified as small (Group III) presented more deterioration and so aflatoxins, however, it was not constant. By density sorting the midget nuts were 
separated and had aflatoxin contamination thus also allowed to reduce aflatoxins. Finally, by NIR, the deteriorated nuts (with possible aflatoxins contamination) were detected more precisely.

The NIR spectrophotometry analysis showed to be the best sorting procedure regarding detection of fungi deterioration and possible aflatoxin contamination with quite high percentage of confidence for the probability of aflatoxin presence. This system is a non-destructive alternative to measure nut deterioration that should be included in a sorting machine (Baye et al., 2006).

Regarding the off-standard nuts that did not meet the standards set through the sorting methods (except for the NIR segregated ones), they could be sent to the Shelling Section of the factory after having their nut quality (deterioration and aflatoxin contamination) inspected by the Quality Control Laboratory. We did not analyse aflatoxins of each nut NIR segregated, separately.

\section{Conclusions}

The physical methods developed and applied for in-shell Brazil nut sorting were able to assess the quality of the batch studied. They also helped to reduce fungal deterioration and aflatoxin contamination as well as standardized color and size of the nuts. Through rejecting midget nuts, dust, dirt and other small particles, the size sorting method lead to some further aflatoxin reduction. Also, by density difference due to nut mass reduction by fungi proliferation $(<1.5 \mathrm{~S} / \mathrm{N}$ ratio), deteriorated nuts were able to be segregated. Finally, when NIR was used, deteriorated in-shell Brazil nuts were more precisely segregated, and the selected nuts had no aflatoxin detected up to the method LOQ with the advantage of no need to de-shell them.

Brazil nuts can be mechanically sorted by means of those physical methods developed. The nut different characteristics and alterations were able to be distinguished and allowed to separate them into healthy and off-standard nuts. Size, weight, color and NIR methods are going to be gathered in one machine to have nuts sorted automatically for better quality and safety for trade. Other methods such as imaging, X-ray and acoustic will be evaluated in the near future. This is the first work carried out on developing physical procedures for specific Brazil nut sorting.

Despite of the quality improvement of the methods applied to the in-shell Brazil nuts, it would be better nuts to be commercialized shelled, as the spoiled ones could be visually segregated and consumers do not eat then (De-Mello and Scussel, 2007; Pacheco and Scusssel, 2007). It would be better policy.

\section{Acknowledgements}

To the Brazil nut factory CIEX and Pacheco, AM from Manaus, Amazonas State, Brazil, for providing the samples; Xavier, JJM for the LC-MS/MS analysis. The UFSC Departments of: Mechanical Engineering (Ogliari, A; Andrade, R; Reinaldo, E; Nagaoka, A) and Rural Engineering (Trebien, DP) for their help to build each sorting apparatus and vibratory engine. The UFPR Departments of: Chemistry and of Forest Engineering and Technology (Zamora, P; Muñiz, G) for the used of NIR spectrophotometer.

\section{References}

AOAC - Association of Official Analytical Chemists. (2005). Official Methods of Analysis of AOAC International $18^{\text {th }}$ ed, Horwitz, W. and Latimer, G. W. Jr. eds. Gaithersburg, Maryland, USA.

Barbin, D. (1999). Seleção eletrônica pela cor na descontaminação de amendoim contaminado com aflatoxinas. Scientia Agricola, 56(2), 371-376. Campo/Pas (2004). Manual de Seguranca e Qualidade para a Cultura da Castanha-do-Brasil. CNI/Senai/Sebrae/Embrapa, Serie Qualidade e Seguranca dos Alimentos. Brasilia, DF, Brazil. Campo PAS, 59p.

Baye, T.M., Pearson, T.C., Settles, A.M. (2006). Development of a calibration to predict maize seed composition using single kernel near infrared spectroscopy. J. Cereal Sci., 43(2), 236-243.

Cetin, A., Pearson, T.C., Tewfik, A.H. (2004). Classification of closed- and open-shell pistachio nuts using voice-recognition technology. Trans. Of the ASAE., 47(2), 659-664.

Delwiches, S.R. (2003). Classification of scab - and other mold-damaged wheat kernels by NIR spectroscopy. Trans. ASAE., 46(3), 731-738.

De Mello, F. R, Scussel, V.M. (2007). Characteristics of in-shell Brazil nuts and their relationship to aflatoxin contamination: criteria for sorting. J. Agric. Food Chem., 55, 9305-9310.

De Mello, F. R, Scussel, V.M. (2009). Detection of in-shell Brazil nuts inner deterioration by near infrared spectrometry of its relationship to aflatoxin contamination: criteria for sorting. Acta Amazonica, in press.

De Oliveira, H.M. (2006). Maquinas selecionadoras para o controle de qualidade dos graos. In Proceedings of the $V$ Congresso Latino-Americano de Micotoxicologia. May, 18-21. Florianopolis, SC, Brazil., 115p.

Dickens, J.W., Whitaker, T.B. (1975). Efficacy of electronic color sorting and hand picking to remove aflatoxin contaminated kernels from commercial lots of shelled peanuts. Peanut Sci., 2(2), 45-50. 
Dowell, F.E., Pearson, T.C., Maghirang, E.B., Xie, F., Wicklow, D.T. (2002). Reflectance and transmittance spectroscopy applied to detecting fumonisin in single corn kernels infected with Fusarium verticillioides. Cereal Chem., $79(2), 222-226$.

European Commission. (1998). Commission Regulation (EC) No. 1525/98 of July 1998, Amending Regulation (EC) 194/97 of 31 January 1997 Setting Maximum Levels for Certain Contaminants in Foodstuffs. Off. J. European Comm., 201, 43-46.

Haff, R.B., Pearson, T.C. (2006). Spectral band selection for optical sorting of pistachio nuts defects. Trans. ASABE, 49(4) 1105-1113.

Haff, R.P., Pearson, T.C. (2007). An automatic algorithm for detection of infestation in X-ray images of agricultural products. Sensing Instr. Food Qual. Safety., 1(3):143-150.

Hirano, S., Okawara, N., Narazaki, S. (1998). Near infrared detection of internally mouldy nuts. Biosci. Biotechnol. Biochem., 62(1), 102-107.

Huff, W.E. (1980). A physical method for the segregation of aflatoxin-contaminated corn. Cereal Chem. , 57, $236-238$.

Huff, W.E., Hagler, W.M. (1982). Evaluation of density segregation as a means to estimate the degree of aflatoxin contamination of corn. Cereal Chem.. 59(2), 152-154.

Huff, W.E., Hagler, W.M. (1985). Density segregation of corn and wheat naturally contaminated with aflatoxin, deoxynivalenol and zearalenone. J. Food Prot., 48(5), 416-420.

McClure, W.F., Farsaie, A. (1980). Dual-wavelength fiber optic photometer measures fluorescence of aflatoxin contaminated pistachio nuts. Trans. ASAE, 23(1), 204-207.

Marklinder, I., Lindblad, M., Gidlund, A., M. Olsen. (2005). Consumers' ability to discriminate aflatoxin-contaminated Brazil nuts. Food Add. Cont., 22, 56-64.

Montgomery, D.C. (2001). Design and Analysis of Experiments. New York: John Wiley \& Sons, 179 pp.

Newing, H., Harrop, S. (2000). European health regulations and Brazil nuts: implications for biodiversity conservation and sustainable rural livelihoods in the Amazon. J. Intl. Wildlife Law Pol., 3, 109-124.

Pacheco, A.M., Scussel, V.M. (2006). Castanha-do-Brasil da Floresta Tropical ao Consumidor. Editograf, Florianopolis SC, Brazil 173p.

Pacheco, A.M., Scussel, V.M. (2007). Selenium and aflatoxin levels in raw Brazil nuts from the Amazon basin. J. Agric. Food Chem., 55,11087-11092.

Pacheco, A.M., Scussel, V.M. (2009). Aflatoxins evaluation on in-shell and shelled dry Brazil nuts for export analysed by LC-MS/MS - 2006 and 2007 Harvests. World Mycotoxin J., 2(3), 295-304.

Palomino, M.E.T., Fonseca, H., Gloria, E.M., Calori-Domingues, M.A., Marques, C. (1998). Avaliação do metodo de triagem para analise de milho contaminado com aflatoxinas pela fluorescencia amarelo-esverdeada brilhante (BGYF Bright Greenish Yellow Fluorescence). Scientia Agrícola., 55(3), 503-508.

Pearson, T.C., Slaughter D.C., Studer, H.E. (1994). Physical properties of pistachio nuts. Trans. ASAE, 37(3), 913-918.

Pearson, T.C., Slaughter, D.C. (1996). Machine vision detection of early split pistachio nuts. Trans. ASAE, 39(3), 1203-1207.

Pearson, T.C. (1999). Use of near infrared transmittance to automatically detect almonds with concealed damage. Lebensmittel-Wissenschaft und-Technologie, 32(2), 73-78.

Pearson, T.C., Wicklow, D.T., Maghirang, E.B., Xie, F., Dowell, F.E. (2001). Detecting aflatoxin in single corn kernels by transmittance and reflectance spectroscopy. Trans. ASAE, 44(5), 1247-1254.

Pearson, T.C., Young, R. (2002). Automated sorting of almonds with embedded shell by laser transmittance imaging. Applied Eng. Agric., 18(5), 637-641.

Pearson, T.C, Wicklow, D.T. (2006). Detection of corn kernels infected by fungi. Trans. ASABE, 49(4), 1235-1245.

Pearson, T.C., Brabec, D., Haley, S. (2008). Color image based sorter for separating red and white wheat. 2(4), 280-288

Pelletier, M.J, Reizner, J.R. (1992). Comparison of fluorescence sorting and color sorting for the removal of aflatoxin from large groups of peanuts. Peanut Sci., 19(1), 15-20.

Rohner, A.W. (1988). Mecânica para Molineros. Oberuzwil, Switzerland, 344p. 
Rotter, R.G., Rotter, B.A., Thompson, B.K., Prelusky, D.B., Trenholm, H.L. (1995). Effectiveness of density segregation and sodium carbonate treatment on the detoxification of Fusarium contaminated corn fed to growing pigs. $J$. Sci. Food Agric., 68, 331-336.

Shetty, P.H., Bhat, R.V. (1999). A physical method for segregation of fumonisin-contaminated maize. Food Chem., 66, 371-374.

Shotwell, O.L., Goulden, M.L., Jepson, A.M., Wolck, W.F., Hesseltine, C.W. (1975). Aflatoxin occurrence in some white corn under loan, 1971. III Association with bright greenish-yellow fluorescence in corn. Cereal Chem., 52, $670-677$

Steiner, W.E., Brunschweiler, K., Leimbacher, E., Schneider, R. (1992). Aflatoxins and fluorescence in Brazil nuts and pistachio nuts. J. Agric. Food Chem., 40(12), 2453-2457.

Teixeira, M.M., Martyn, P.J., Hara, T., Rodrigues da Cunha, J.P.A. (2003). Propriedades físicas e aerodinâmicas aplicadas ao projeto de maquinas de limpeza para grãos de milho. Engenharia na Agricultura, 11(1-4), 52-57.

Tyson, T.W., Clark, R.L. (1974). An investigation of the fluorescent properties of aflatoxin infected pecans. Trans. ASAE, 17(5), 942-945.

Wicklow, D.T., Pearson, T.C. (2006). Detection and removal of single mycotoxin contaminated maize grains following harvest. In the Proceedings of the $9^{\text {th }}$ International Working Conference on Stored Product Protection, Campinas, São Paulo. Brazil. Abrapos, 106-119.

Xavier, J.J.M., Scussel, V.M. (2008). Development of methodology by LC-MS/MS for aflatoxins $B_{1}, B_{2}, G_{1}$ and $G_{2}$ in Brazil nuts for export. Int. J. Environ. Chem., 88(6), 425-433. 


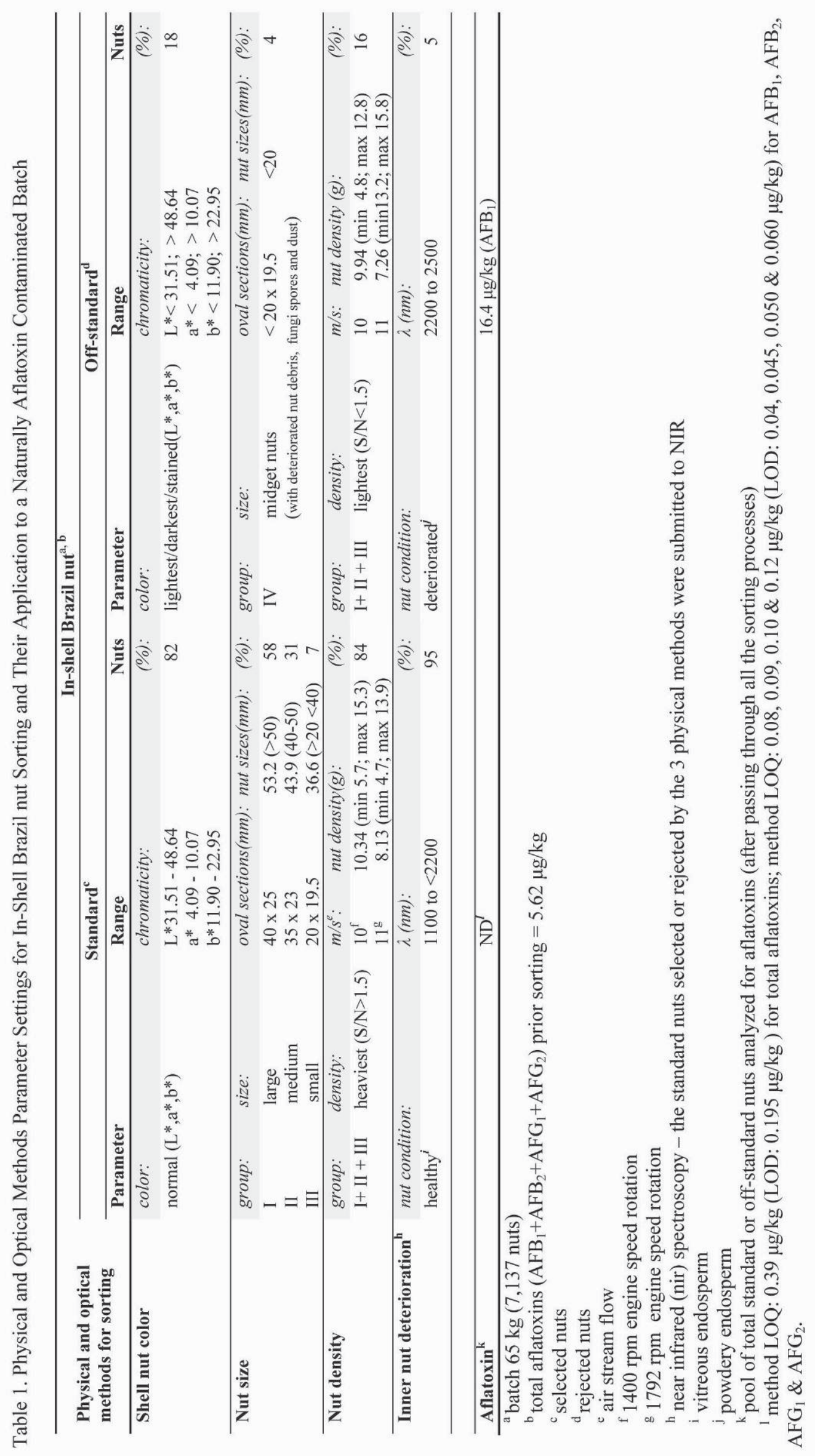




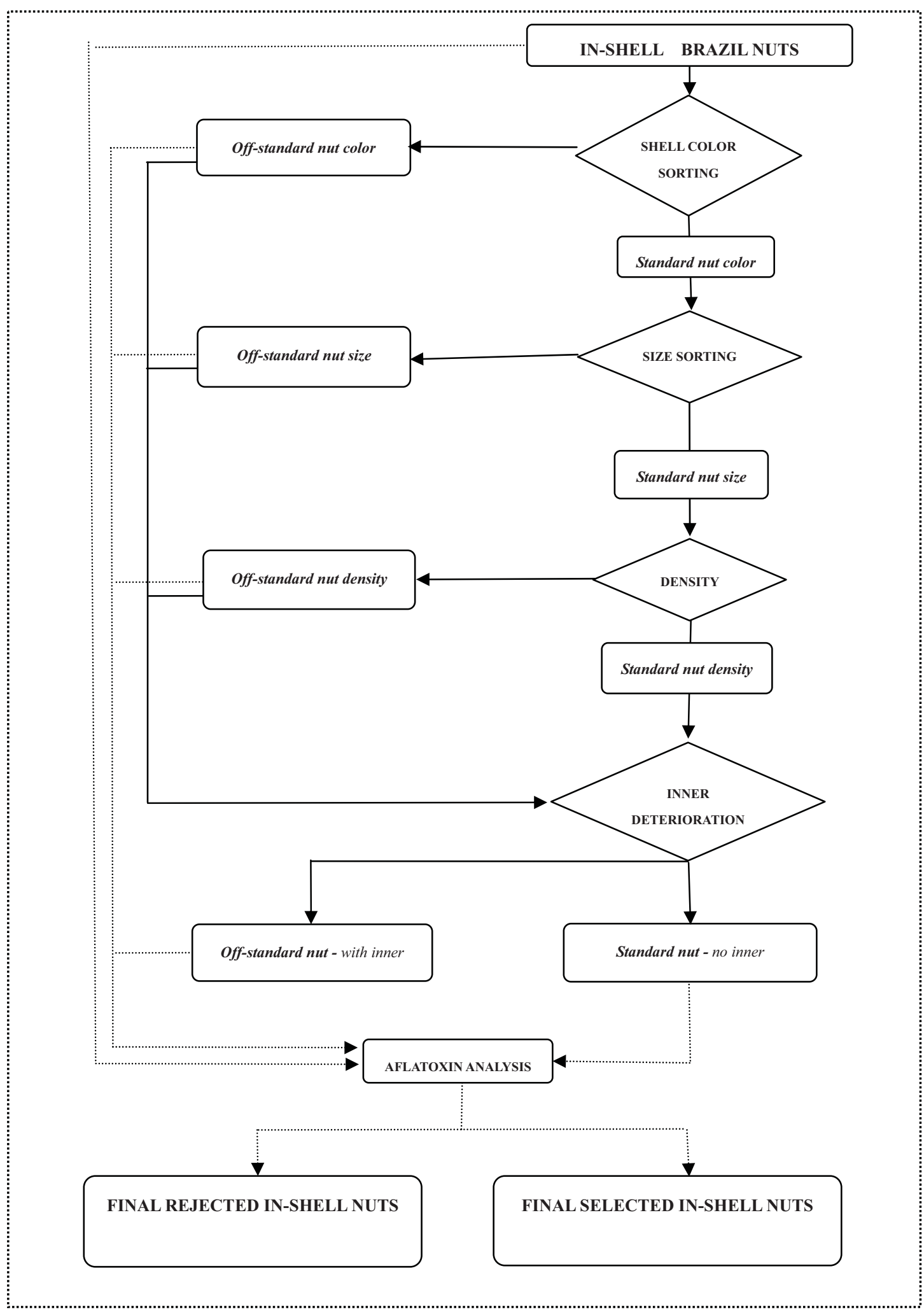

Figure 1. Flow chart of the physical and optical methods applied for in-shell Brazil nuts sorting showing the off-standard/rejected nuts and aflatoxin analysis steps 


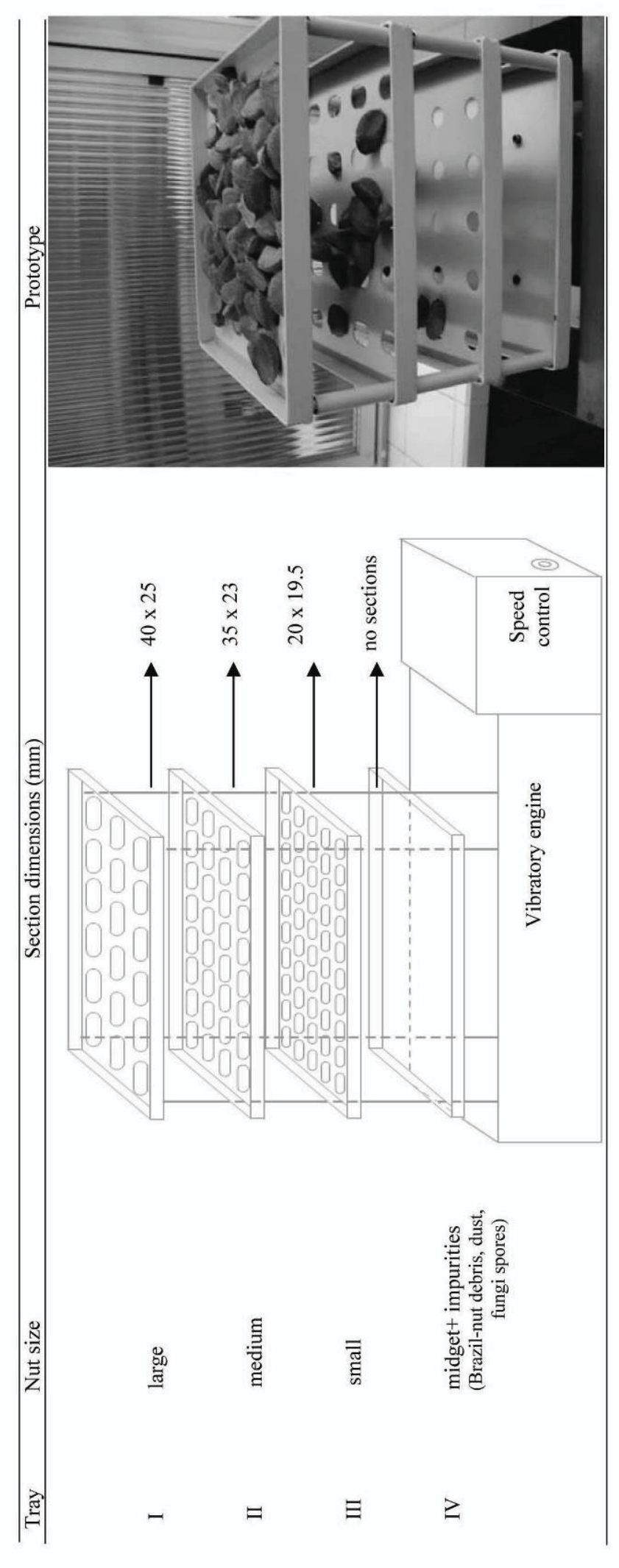

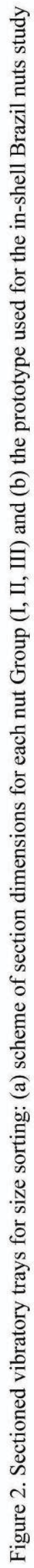


(a)

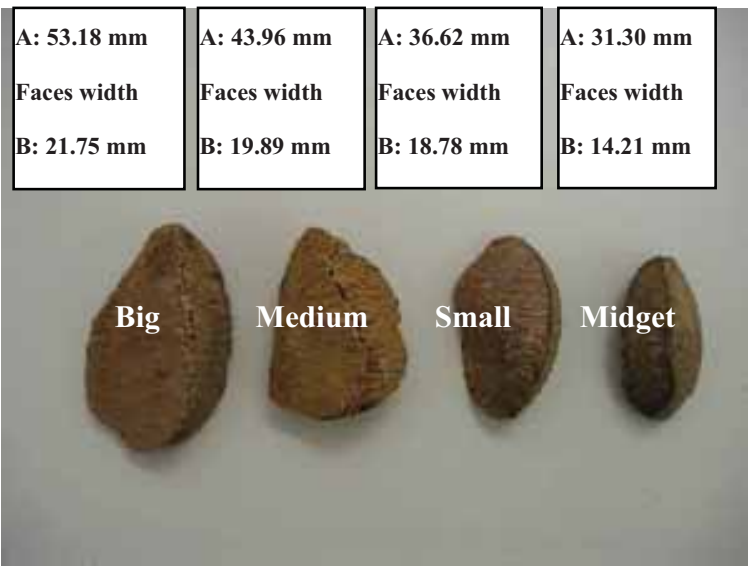

Lenght

A

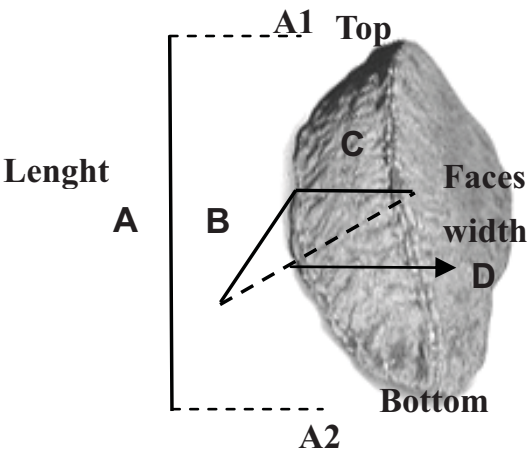

(b)

Figure 3. In-shell Brazil nuts (a) classified by vibratory trays and (b) points of nut dimensions taken for size tray sections design

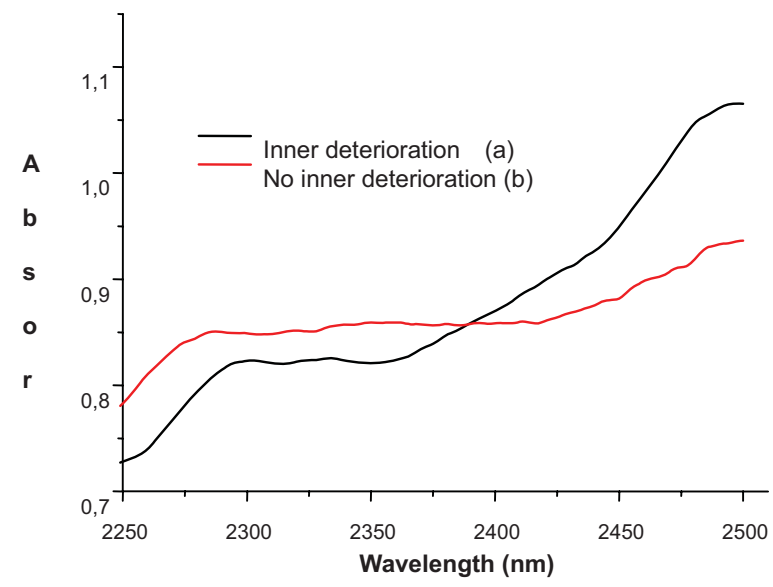

Figure 4. Near infrared curves obtained from two in-shell Brazil nuts showing differences on absorbance intensities: (a) nut presenting inner-deterioration (off-standard) and (b) nut without deterioration (standard). 